\title{
Research on the Occupational Emotion of Counselors in Universities Based on Behaviorism Theory
}

\author{
Jiang Li \\ Faculty of Chinese Language and Culture \\ Guangdong University of Foreign Studies \\ Guangzhou, China \\ 276038327@qq.com
}

\author{
Xiaohua Ke* \\ Cisco School of Informatics \\ Guangdong University of Foreign Studies \\ Guangzhou, China \\ carrieke@gdufs.edu.cn \\ *Corresponding author
}

\begin{abstract}
Cultivating occupational emotion for counselors in universities is an important part of professionalizing them. . This research, based on the behaviorism theory in psychology, explores the generative mechanism of university counselors' occupational emotion from such perspectives as external environment, needs of career development, role definition, job responsibilities, income, management, motivation mechanism and counselor team. It puts forward feasible measures to cultivate counselor's occupational emotion. These measures are: creating sound environment, emphasizing academic research, giving more trainings, making clear the job objectives and responsibilities, improving evaluation system and motivation and guarantee mechanism as well as implementing policies.
\end{abstract}

Keywords-behaviorism theory; counselors; occupational emotion; generative mechanism; cultivation mechanism

\section{INTRODUCTION}

As one kind of emotion, the occupational emotion is one's sentiment towards occupation.. Specifically, It refers to the degree of satisfaction of a counselor towards his occupation. It is a special feeling formed on the basis of the counselor's knowledge, judgment and thinking of this occupation[1]. His sense of identity and responsibility, working attitude and enthusiasm will directly influence college students' sound growth. Positive occupational emotion enables a counselor to regard his job of dealing with students as his job, and thus forming an awareness of need and thorough understanding of his job so that he will love his job and actively engage himself in it. On the contrary, negative occupational emotion leads a counselor to treat his job as a means of making a living, and to think more of his gains and losses and material benefits, to lack a sense of career identity and responsibility. In this sense, it is easier for him to form a negative attitude towards his job.

Conducting a research on the counselor's occupational emotion is very important and necessary and is of great theoretical and practical significance. In recent years, more and more researchers have paid attention to the counselor's occupational emotion, which gradually becomes one of the hot topics in terms of student work. Such research involves theoretical knowledge in various areas including management, psychology and pedagogy. However, according to the existing literature, researchers have all emphasized the empirical research but not dig into the theoretical base and formation mechanism of the counselor's occupational emotion. Therefore, their researches are short of theoretical support and the cultivating measures put forward by them are not systematic enough. These are the weaknesses of the current researches on the counselor's occupational emotion. Based on the behaviorism theory in psychology, this paper deducts and explains the generative mechanism of the occupational emotion of counselors and puts forward feasible measures for cultivating the emotion.

\section{BEHAVIORISM THEORY}

Behaviorism came into being between the end of the $19^{\text {th }}$ century and the beginning of the $20^{\text {th }}$ century, and is represented by John Broadus Watson, Burrhus Frederic Skinner, William James, Carl Georg Lange, Albert Bandura, and so forth. It features two characteristics: the first is denial of consciousness and advocacy of psychological research, and the second is disapproval of introspection and approval of experimental approach. In the views of behaviorist psychologists, consciousness is invisible and untouchable, thus unable to be studied objectively. Therefore, the research object of psychology should not be consciousness but rather observable events, that is, behaviors.

John Broadus Watson established the Stimulus-Response Model, which maintains that all aspects of a behavior, including emotion, mood and thought, can be discussed with objective terms of stimulus-response. His principal behaviorist theory contains five major points, namely, behavior, thinking, habit, mood and personality, all being elaborated from the perspective of form and integration manner of habit. Burrhus Frederic Skinner is a neo-behaviorist who holds that most behaviors of animals and humans are operant, conducted by an individual in a normal state. When a behavior is strengthened, its rate of occurrence will increase. Reinforcement is the crux of operant behavior. Without reinforcement, there would be no condition that changes the rate and strength of a behavior and then such behavior will disappear gradually. American psychologist William James and Danish physiologist Carl Georg Lange put forward respectively an emotion theory with the same content and therefore it is named James-Lange Theory. The theory proposes that when the body undergoes changes, a person can feel them, which in fact are emotions. They emphasize that emotion is the product of vegetative neural activities. A feeling stimulates a physiological response, and then the response evokes emotional experience. Later scholars name their theory the Peripheral Theory of Emotion. James views that emotion is the feeling of the body and that 
physiological change of the organism occurs before emotion. Therefore sorrow is caused by weeping and terror by trembling. Lange considers that emotion is a result of visceral activities, and specially stresses the relationship between emotion and vascular change. However, the two psychologists overstate the role of vegetative nervous system and underestimate the role of central nervous system in adjustment and control. Another behaviorist psychologist, Albert Bandura, lays emphasis on observational learning, which means learning new behavior through observation of other people's behaviors and results. This type of study does not require the learner to make direct reaction or experience reinforcement in person, but only study through observation of others' behaviors and reinforcements. Viewed from the development course of behaviorist research, the research perspective has been gradually sheered from earlier focus on explicit behavior that takes the behavior as controlled object which is mechanical and passive, to focus on subjective cognitive ability of the behavior as well as on the influence of factors like cognition, value, psychology, morality of the behavior on his behavior [2]. The research result of this theory is that in emotion cultivation special attention should be paid to in-person practice and to promoting the change of individual feeling through behavior, thus stimulating corresponding emotions.

Behaviorism theory is profoundly conducive to research on occupational emotion of counselors in the following aspects. In the first place, it attaches importance to the influence of behavior on the development of a person, to be exact, the influence of acquired knowledge. Trough elimination and control of influence of negative factors, it provides more positive education and push people to form good habits, thus helping cultivate positive occupational emotion. In the meanwhile, the theory underlines the function of education and environment, which implies that all behaviors take place in certain environment. Without the conditions provided by an environment, learners will not be able to acquire knowledge from behaviors. Social environment is the external objective condition for mental and health development of a person, and also plays a certain refraining role. Hence, this serves as an important theoretical support for research on the influence of school and social elements on the occupational emotion of counselors.

\section{GENERATIVE MECHANISM OF INSTRUCTOR's OCCUPATIONAL EMOTION BASED ON BEHAVIORISM THEORY}

It is asserted by Behaviorism Theory that emotion is the organism's reaction to a particular environment; a particular environment causes a corresponding reaction. Prior to the generation of emotion, there must be a corresponding physical behavior. A real consciousness toward a certain situation emerges when humans have physical behaviors, and this kind of consciousness may change human's first impression toward that situation. That is to say, university counselors produce their own attitudes and opinions by personal practice and form their deep consciousness about the occupation. And this type of consciousness is naturally related to the emotion of love or hate toward the occupation of school instructor. The generative mechanism of school instructor's occupational emotion can be reflected in the following six aspects.

\section{A. The Reaction to External Environment}

Emotion is the essential means for organisms to survive, grow and adapt to environment. Physiological reaction provoked by emotion and mood can mobilize the energy within the body and leave the organism in a fine statement to adapt to social environment and seek for better conditions to live and grow. According to B.F. Skinner's theory, in the relation between human and environment, environment plays the active role, while human, the passive one. Environment influences humans in an active way and causes all the human behaviors. Behaviors can be controlled as long as environment is controlled. The occupational emotion of counselors is also affected by the external world. Counselors know about the relevant policies made by state and schools, and feel the ideas and opinion hold by the society, schools and families on the occupation of counselor. Inevitably, these ideas and opinions will have impact on their behavior. Thus, creating a sound social environment where counselors are mostly respected, loved and cared and implementing favorable policies and measures are helpful for the counselors to form good occupational behavior and emotion.

\section{B. The Reaction to the Need for Occupation Development}

Behaviorism Theory underlines the effect of selfadjustment, holding that to some extent human controls their behaviors by goals and plans set by ourselves. As for counselors, they have the need to obtain higher job titles. Therefore, it is essential for them to make a good career plan, set up goals and schemes to guide their self-control, which enables them to determine priorities among various goals, organize a system of past behaviors and future behaviors and take corresponding actions in order to meet the job requirements and achieve their objectives.

\section{The Reaction to the Role and Responsibility of the Occupation}

Behaviorism Theory claims that most behaviors of animals and humans are operant. This type of behavior has changeable feature of adapting to the environment. The role and responsibility of this occupation clearly specified the rules that counselors must abide by . It defines the occupational behaviors and development direction of counselors by enhancing the operation systematically as well as excluding and controlling some unfavorable factors. If they behave as schools expect, the factors contributed to this kind of behavior will be enhanced by schools; otherwise, schools will punish the action that doesn't conform to its regulations so as to correct it. This is the external enhancement to control actions.

\section{The Reaction to Income}

John B. Watson's S-R theory claims that all aspects of behavior, including emotion, mood and thought can be discussed with "S-R" terms. Counselors have some expectations on working conditions, reward, skill improvement and income. When income cannot meet their expectation, they are inclined to produce such negative feelings as unhappiness, anger, frustration and anxiety and react in a negative way; while income is greater than expected, they would be happy, exited, elated and react in a positive way. These emotions are the expressions of their true feelings and have the function of 
conveying information and communicating. Positive emotion and mood have coordinative and primitive effects on behaviors; while negative ones have destructive effects.

\section{E. The Reaction to Administrative and Incentive Mechanism}

As the representative of Behaviorism Theory, B.F. Skinner especially highlights the effect of enhancement. He maintains that enhancement is the crux of operative behaviors. When behavior is enhanced, this behavior will occur more frequently. Without enhancement, the conditions that can control the frequency and intensity of behavior will no longer exist and this behavior will also disappear gradually. In order to develop good occupational emotion of counselors, it is also necessary to enhance the behaviors and habits of a new counselor ; to specify the responsibilities and regulations; to build a scientific and reasonable index system of performance evaluation; to let the performance evaluation play the role of appraisal, inspiration and guidance; to set up good examples with the view of inspiring the excellent instructors; to build the withdrawal mechanism to eliminate the incompetent ones. With the help of administrative and incentive mechanism, counselors tend to meet the demand of specialization and professionalization and develop good occupational emotion by continuously accumulating.

\section{F. The Reaction to the Counselor Team}

The main viewpoint of Albert Bandura's Behaviorism Theory is observation learning. Namely, new behavior is learned through the observing other people's behaviors and its consequences. According to this theory, the construction of a school counselor team is of great significance. An optimistic, healthy, united and competitive team has great impact on counselors. . Due to the team's style construction and the good example set by those experienced ones, new school instructors have pattern to follow, have goals to pursue, which helps to raise their professional self-identity and the sense of honor.

\section{THE ENLIGHTENMENT FOR COUNSELORS}

\section{A. Create a Sound Environment for New Counselors to Promote Their Positive Occupational Emotion}

According to the behaviorism-based generative mechanism of counselors' occupational emotion, counselors should practice more before their professional emotion takes shape. The personal practice can help them form a deep understanding for their profession and therefore generate positive occupational emotion. Emotional experience plays an important role in the formation of career belief. Positive emotions or feelings can promote and intensify the formation of career belief while passive ones have a negative effect on it. So colleges and universities should provide good working and living environment for counselors, create an atmosphere of valuing them, respecting them and caring for them, emphasize the value and significance of their work, provide a smooth channel for their career development, help them solve various problems and take effective steps to promote their development and success. Meanwhile, according to the theory of observational learning of behaviorism, colleges and universities should establish a positive, cohesive and powerful student affairs team. Elder counselors should teach, assist and instruct new counselors, and the counselors' team should strengthen its internal communication, so as to build a united and cooperative collective and strengthen its trust, belongingness and efficacy. Theses help counselors acknowledge and accept the value, attitude and behaviors promoted by this team during the process of their working practice.

\section{B. Strengthen academic status and discourse right}

Being in short of academic backgrounds and scientific research achievements, counselors usually have low academic titles and no sense of academic accomplishment. The colleges and universities should create a condition to improve this situation. In the process of performance appraisal, the counselors' practical working performance should be stipulated as the primary factor to consider. Meanwhile, certain requirements regarding scientific research should be proposed to lead counselors to reinforce their consciousness of scientific research, to pay more attention to theoretical researches and to make more research achievements. The counselors' work can be classified into six directions including ideological and political, education, student affairs management, psychological health education, social practice, development, campus culture development and career guidance. Like professional teachers, counselors can establish an innovation group of scientific research and divide it into small teams in different research directions, each with a academic leader. Research programs declared in different levels should take in counselors and implement modular management. Counselors can choose one or two of these programs as their major research directions. Only by emphasizing academic research and making great research achievements can they become experts in the field of student affairs research and attain relevant academic status and professional discourse right.

\section{Organize multi-layered training in Occupational skills}

Training and further study play a significant part in enhancing counselors' professionalization. On the one hand, colleges and universities should cultivate qualified personnel major in student affairs by developing relevant disciplines. Counselors major in postgraduate level should be set up and can be divided into different directions, such as ideological and political education, student affairs management, psychological consultation, career guidance. Colleges and universities should encourage counselors to study for relevant master's degrees or doctor's degrees and develop the elites who aim at working as long-term counselors into experts and foregoers in this filed. On the other hand, multilevel and multiform counselor training system should be reinforced and completed. With provincial training as the stress and on-campus training as the principal, other forms of training including making investigations, studying for degrees, doing researches, attending seminars and secondments should be held to achieve all-round and systematic training in theories and practice.

\section{Redefine counselors' responsibilities and role}

Considering the present circumstance where counselors' role and work objectives are both vague, it is necessary for management of universities to redesign counselors' work, to further define their responsibilities and roles, and to reinforce process monitoring, so that various sorts of tasks and plans can be well implemented. Responsibility system for work targets should be promoted to prevent counselors from being caught in 
routine work. It is necessary to make counselors harbor the consciousness that ideological and political education is the core, student development guidance is the principal and student affairs management is the basis. Counselors should be allowed to take part in and to contribute opinions to the design of work targets and work responsibilities so as to better understand the range of their functions and powers and to make the role of their work better meet their expectations. Only in this way can they be more conscious of the significance, competence, initiative and effect of their work and better stimulate their enthusiasm and motivation. Meanwhile, the system of student affairs management should be further clarified to coordinate student affairs department and other functional departments in the university.

\section{E. Update the Scientific Evaluation System, Implement the Feedback Mechanism and Improve the Counselors' Sense of Achievement}

Nowadays, the evaluation system that China's colleges and universities use often applies the method of rewards and punishments, but does not set any parameter that is related to the professionalization and specialization of counselors. Therefore, improving a scientific evaluation system should aim at the overall development of the counselors' quality, care for the process of the assessment, focus on the individual difference and underline the diverse characteristics of evaluation subjects.

\section{F. Complete the Incentive and Security Mechanism to Maximize Counselors' Personal Development}

According to management science, what can truly stimulate the administrators' initiatives and make them outdo themselves are as follows: to give them a sense of achievement, to provide them a challenging job, to get social recognition for their work performance and to improve their responsibility and career. The behaviorism also offers a theoretical reference to the practice of meeting the counselors' career development needs. For example, if the new counselors' needs cannot be met, they will easily be prone to the negative emotion, which may destroy the career. Therefore, it is essential for the counselors' team to provide necessary security mechanism, resort to both material and mental stimulation and enhance the counselors' development. This will, to a great extent, determine the process of their professionalization and specialization. Generally speaking, the security mechanism should contain the evaluation and engagement of counselors' professional titles, the opportunity for their development and the conditions for their daily working. Thus, the colleges and universities should establish the evaluation system of professional titles which is suitable for the features and regulars of counselors' works, perfect the promotion system of administrative rank and unblock the distribution channels. They should also link the performance evaluation to the rewards and punishment, which means fulfill counselors' personal development with various stimulations like model, reputation, material, emotion and promotion. What's more, they should make new counselors achieve career development and realize the life value in their own positions. Finally, they can professionalize and specialize counselors' team through such system and mechanism.

\section{G. Enhance Counselors' Occupational Prestige and Implement Relevant Policies Effectively}

The social evaluation will influence the new counselors' opinions on their occupation. When counselors have good occupational prestige, new counselors will strongly identify with it. Currently, the CPC and the government have paid much attention to education. They have carried out a series of good policies and improved the teacher's status and reputation. As a part of the teaching team in colleges and universities, counselors are no exception. It is reasonable that counselors have good occupational prestige, but the fact is that their social evaluation and salary are lower than the specialized teachers, their function and effect are even unknown by the students' parents and the relevant policies are unfulfilled. The enhancement can be undertaken in three aspects: first, the whole society should honor teachers and widely publicize the importance of the education, teachers and counselors. They should also report and reward the excellent teachers and counselors and make people better recognize, understand and value their occupation. Second, the relevant sectors should supervise the implementation of the policies and the formulation of the school rules and regulations. Last but not least, the relevant sectors should build a channel and mechanism of social communication so that the counselors can communicate with the workers of social departments and widen the development ways. Some virtuous and competent counselors even seek prominent working positions in the local party and government offices. Consequently, after fully realizing the attention to education and the respect to counselors from the whole society, the new counselors can better recognize and evaluate this occupation and cultivate positive occupational emotion.

\section{ACKNOWLEDGMENT}

The authors would like to express their sincere acknowledgements to the University innovation projects of Guangdong province (2014), and the Research project of Ideological and Political Education of Guangdong Province (2014ZK023) as research topics and sponsored this study.

\section{REFERENCES}

[1] Y. Changrui, S. Li, Sh. Bo, On the value and expression of counselors' occupational emotion. School Party Development and Ideological Education, 2012(5), pp.123-127

[2] F. Meiping, Behaviorism and its Research Paradigm. Journal of East China University of Science and Technology (Social Sciences),2000(4), pp.61-63 